\title{
Colonoscopic perforations: Single center experience and review of the literature
}

\author{
Şükrü Çolak, Bünyamin Gürbulak, Hasan Bektaș, Ekrem Çakar, Yiğit Düzköylü, Savaș Bayrak, Ayhan Güneyi
}

\begin{tabular}{|c|c|}
\hline \multirow[t]{5}{*}{ ABSTRACT } & $\begin{array}{l}\text { Objective: latrogenic colonic perforation is a well-known complication that can increase mortality and morbidity } \\
\text { in patients undergoing colonoscopy. Closer follow-up and a well-planned treatment strategy are required when } \\
\text { perforation arises as a complication. The aims of this study are to (1) report our experience with a large colonos- } \\
\text { copy series; ( } 2 \text { ) evaluate the underlying mechanisms of iatrogenic colonic perforation; (3) discuss the ideal period } \\
\text { between onset and treatment; and (4) review the current literature regarding the management of iatrogenic colonic } \\
\text { perforations. }\end{array}$ \\
\hline & $\begin{array}{l}\text { Material and Methods: Patients who underwent colonoscopy between January } 2005 \text { and May } 2015 \text { at a single cen- } \\
\text { ter were reviewed retrospectively. Procedures during which colonic perforations occurred were documented and } \\
\text { analyzed. }\end{array}$ \\
\hline & $\begin{array}{l}\text { Results: Between January } 2005 \text { and May 2015, 31,655 patients underwent colonoscopy and 5,214 patients under- } \\
\text { went recto-sigmoidoscopy at our center. Thirteen of these procedures were associated with perforation. The perfo- } \\
\text { ration rate was found to be } 0.041 \% \text {. The most frequent locations of perforation were (a) the rectosigmoid junction, } \\
\text { (b) the proximal rectum, and (c) the sigmoid colon. Management included surgical treatment in } 11 \text { patients and } \\
\text { conservative management in } 2 \text { patients. Twelve patients (92.31\%) were discharged uneventfully, and death occurred } \\
\text { in one }(7.69 \%) \text { patient. }\end{array}$ \\
\hline & $\begin{array}{l}\text { Conclusion: Although they are rarely encountered, colonic perforations are serious complications of colonoscopy. A } \\
\text { high index of clinical suspicion is required for early diagnosis and appropriate treatment. Age, co-morbidities, the } \\
\text { location and size of the perforation, and the time interval between onset and diagnosis should be evaluated, and } \\
\text { the treatment approach should be planned accordingly. }\end{array}$ \\
\hline & Keywords: Colon perforation, colonoscopy, iatrogenic bowel perforation \\
\hline
\end{tabular}

Cite this paper as:

Çolak Ş, Gürbulak B, Bektaş

H, Çakar E, Düzköylü Y, Bayrak

B, Güneyi A. Colonoscopic perforations: Single center experience and review of the literature. Turk J Surg 2017;

33: 195-199.

Clinic of General Surgery, İstanbul Training and Research Hospital, İstanbul, Turkey

Address for Correspondence Bünyamin Gürbulak e-mail:bgurbulak@gmail.com

Received: 23.03.2016 Accepted: 25.05.2016

Available Online Date: 25.04.2017

(C) Copyright 2017

by Turkish Surgical Association

Available online at

www.turkjsurg.com

\section{INTRODUCTION}

Colonoscopy is accepted as the gold standard imaging modality for the diagnosis of colon and distal ileum diseases. It aids the detection of smaller lesions and tissue sampling and also functions as a therapeutic procedure for intestinal diseases. Similar to other invasive procedures, colonoscopy has been associated with various complications; among these, perforation is the most important. latrogenic colonic perforation has high rates of mortality and morbidity. It is mainly divided into two categories: diagnostic and therapeutic $(1,2)$. Management includes both medical and surgical approaches. However, the best approach for treatment depends on various factors, such as the patient's general condition, age, comorbidities, and, most importantly, the time between the onset and diagnosis of perforation. In this study, we aimed to evaluate the incidence of perforation in a large colonoscopy series, discuss patient management strategies, and analyze the clinical consequences of iatrogenic colonic perforation.

\section{MATERIAL AND METHODS}

Between January 2005 and May 2015, a total of 31,655 lower GIS endoscopies were performed at our center. Patients with iatrogenic colonic perforations were investigated retrospectively. All procedures were conducted under sedoanalgesia. The procedures were performed by 27 endoscopists, including 24 general surgeons and 3 gastroenterology specialists. The experience of the endoscopists varied between 2 and 15 years.

We analyzed the demographic characteristics of the patients, the type of procedure (therapeutic or diagnostic), indications for colonoscopy and associated colonic disease, location and detection time of perforation, management strategy (operative or nonoperative), and complications.

The perforations were detected either during colonoscopy by observing a visible defect in the colonic wall (mesenteric or antimesenteric side) or after the procedure by detecting free intra-abdominal air upon radiological examination. Patients who complained of abdominal pain or distention following 
colonoscopy were initially evaluated by abdominal x-ray. All patients with generalized peritonitis and free intra-abdominal air underwent surgical intervention.

Ethics committee approval was not required due to the retrospective nature of the study. All data were collected from the accessible computer database system of the hospital. Written informed consent was obtained from all patients included in this study. The information was collected in accordance with the Declaration of Helsinki.

\section{Statistical Analysis}

Statistical analyses were performed using the Statistical Package for the Social Sciences (IBM Corp.; Armonk, NY, USA) 22.0 software package.

Table 1. Distribution of procedures by year

\begin{tabular}{|lccc|}
\hline Year & Colonoscopies & RSS & Perforations (n) \\
\hline 2005 & 594 & 170 & - \\
\hline 2006 & 1620 & 410 & - \\
\hline 2007 & 2241 & 595 & 2 \\
\hline 2008 & 3024 & 950 & 1 \\
\hline 2009 & 4050 & 800 & 1 \\
\hline 2010 & 5184 & 500 & - \\
\hline 2011 & 4428 & 650 & 2 \\
\hline 2012 & 5004 & 550 & 1 \\
\hline 2013 & 4527 & 562 & 4 \\
\hline $2014-2015$ & 983 & 27 & 2 \\
\hline January to May & & & \\
\hline Total & 31655 & 5214 & 13 \\
\hline
\end{tabular}

RSS: rectosigmoidoscopy

\section{RESULTS}

Lower GIS endoscopies included 5,214 recto-sigmoidoscopy (RRS) and 31,655 colonoscopy procedures (Table 1). Perforation occurred in $13(0.041 \%)$ patients. Perforated patients included five men and eight women. Their mean age was 63.8 (range 44 to 77) years. Indications for colonoscopies were as follows: sub-ileus ( $n=1266)(4 \%)$, constipation and abdominal pain $(n=949)(3 \%)$, and investigation of the etiology of anemia $(n=1900)(6 \%)$. Anatomic distribution of the perforations included the (i) proximal rectum ( $\mathrm{n}=3$ ), (ii) rectosigmoid junction $(n=6)$, (iii) sigmoid colon ( $n=3)$, and (iv) ascending colon $(n=1)$. Overall, iatrogenic perforations were recorded by 13 endoscopists who had variable years of endoscopic experience. Eight of the endoscopists had a mean experience of three (range two to five) years. Endoscopic experience varied from 5 to 10 years for three endoscopists and 10 to 15 years for two endoscopists. The times of diagnosis and the treatment approaches for each anatomic location of perforation are shown in Table 2. Perforation occurred during the procedure in nine patients. Seven of the patients whose colonic wall integrity was disrupted had abdominal pain, defense, or guarding as clinical symptoms. The other two patients did not show clinical symptoms of abdominal pain, guarding, or defense; in these patients, the site of perforation was found to be on the mesenteric side. In all patients who experienced perforation during the procedure, the management of choice was surgical. In all patients, primary colon repair was performed. In addition to primary colon repair, colostomy was performed in two patients and ileostomy in one patient.

Perforation was detected in four patients after colonoscopy. One patient was admitted to the emergency clinic due to acute abdominal pain following colonoscopy. Abdominal Xray of the patient revealed free air under the diaphragm; the patient underwent an operation about six hours after the colonoscopy procedure. Perforation was observed in the rectosigmoid junction and treated with primary repair. Subcutaneous emphysema was observed in the neck of one patient

Table 2. Demographics, localization, time of diagnosis, and treatment of patients with perforation

\begin{tabular}{|c|c|c|c|c|}
\hline Age & Gender & Localization (year) & Time of diagnosis & Treatment \\
\hline 76 & M & Rectosigmoid junction (2007) & Perioperative & Primary repair \\
\hline 68 & M & Rectosigmoid junction (2008) & Perioperative & Primary repair \\
\hline 71 & $\mathrm{~F}$ & Sigmoid colon (2009) & Perioperative & Primary repair \\
\hline 51 & $\mathrm{~F}$ & Sigmoid colon (2011) & Perioperative & Primary repair and ileostomy \\
\hline 69 & M & Rectum (2011) & Perioperative & Primary repair \\
\hline 44 & $\mathrm{~F}$ & Rectosigmoid junction (2012) & 6 hours later & Primary repair \\
\hline 68 & $\mathrm{~F}$ & Rectum (2013) & Perioperative & Primary repair and colostomy \\
\hline 77 & $\mathrm{~F}$ & Rectosigmoid junction (2013) & Perioperative & Primary repair \\
\hline 56 & $\mathrm{~F}$ & Rectosigmoid junction (2013) & Perioperative & Primary repair and colostomy \\
\hline 69 & $\mathrm{~F}$ & Rectum (2014) & Perioperative & Primary repair \\
\hline 60 & $\mathrm{~F}$ & Sigmoid colon (2015) & 24 hours later & Exitus (refusal of surgery) \\
\hline
\end{tabular}


eight hours after the colonoscopy procedure. On exploration, perforation was detected in the proximal rectum. Primary repair with loop colostomy was performed due to peritonitis symptoms and accompanying comorbidity. One iatrogenic colon perforation occurred as a result of polypectomy. The patient had a history of repetitive polypectomy; further polypectomy was performed for polyps larger than $1 \mathrm{~cm}$. He had fever and abdominal pain 12 hours after the colonoscopy procedure and was admitted to the emergency department. Subdiphragmatic free air was detected under the diaphragm in an abdominal X-ray. Secondary colon perforation was considered for the patient as a result of polypectomy. There were no peritonitis symptoms. The patient was discharged without complications with broad spectrum antibiotherapy. The other patient was admitted to hospital due to abdominal pain and symptoms of anemia; perforation was diagnosed 24 hours after the colonoscopy procedure. Due to rejection of surgery by the patient, it was decided to follow up the patient with medical treatment. Unfortunately, the patient died due to onset of sepsis 92 hours after the procedure.

The mortality rate was found to be $7.69 \%$ ( 1 in 13 patients). The average length of hospital stay was 15 (range: 5 to 48) days.

\section{DISCUSSION}

Colonoscopy is the gold standard for the diagnosis and followup of colonic diseases (3). Despite its superiority in diagnostic and therapeutic use, it can lead to serious complications. Previous reports have documented a wide array of complications, including electrolyte imbalances that occur during preparation for colonoscopy and sedation during the procedure. Therefore, patient monitoring during the procedure is important to reduce and prevent these complications (4). Other complications are iatrogenic in nature; these include hemorrhage and perforations. Perforation rates are reported to range between $0.02 \%$ and $0.8 \%$ for diagnostic colonoscopy and between $0.15 \%$ and $0.3 \%$ for therapeutic colonoscopy $(1,2)$. Regarding technique, endoscopic sub-mucosal dissection (ESD) is known to carry a higher perforation risk than endoscopic mucosal resection $(E M R)$ or polypectomy $(5,6)$. The rate of hemorrhage has been reported to be $1 \%$ to $2 \%$ and is more visible after polypectomy and dilatation of structures compared to other procedures (7-9). Perforation may occur from direct mechanic effects (sharp edge) of the colonoscope, barotrauma, or thermal burns during polypectomy (5). While perforation resulting from direct mechanic effects is often seen in the recto-sigmoid junction and strictures, perforation resulting from direct barotrauma is most frequently seen in the cecum zone $(1,6)$.

Perforations that occur during therapeutic processes such as polypectomy are seen during polypectomies of polyps greater than $2 \mathrm{~cm}$ in size, similarly to our right colon case. Compared to flexible rectosigmoidoscopy, perforation rates during colonoscopies are two or four times higher $(8,9)$. In our study, no perforations occurred during rectosigmoidoscopy, thus obviating the need for a comparison of both approaches. Perforations are known to occur commonly at the recto-sigmoid junction. Reported reasons include angulation and transition challenges at the recto-sigmoid junction and thinning of the colonic wall at the ascending colon (10-12). In our series, the rate of perforation was seen most frequently (46\%) in the recto-sigmoid junction.
Of the three (mechanical, barotraumas, and thermal) previously described mechanisms associated with colonoscopic perforations, mechanical is known to be the most common (13-15). It occurs after forcing the tip of the apparatus without direct visualization, making loops in the far areas, or penetrating a diverticulum $(16,17)$. Barotrauma is another important mechanism; it results from excessive gas insufflation leading to linear tear or full-thickness perforation of the serosa. Perforations due to barotrauma may occur in the right colon due to its width $(18,19)$. They can occur not only in the cecum but also in high-pressure zones such as angulations in the sigmoid colon or herniated loops that enter into the inguinal and ventral sacs (20).

For perforations related to colonoscopy, structural colonic pathologies (diverticular disease, inflammatory bowel diseases, megacolon) and patient-related factors (age, female gender, accompanying illnesses, previous abdominopelvic surgeries) have been reported as prognostic factors. Previous studies have shown that patients over 65 years of age present significant risks for perforation (1, 21-23). In some studies, it has been reported that the perforation rate in patients over 75 years of age can increase by four to six times compared to that in young patients $(24,25)$. Korman et al. (1), Anderson et al. (6), and Handami et al. (21) stated that female gender carries a higher risk for perforation, while Arora et al. (23) documented no correlation with gender. In our study, eight patients (61.5\%) were female. Perforations in four patients were due to inadequate bowel preparation (sub-ileus state), and the other four patients had histories of gynecological surgery.

Handami et al. (21), Arora et al. (23) and Gatto et al. (24) observed that the perforation rate is higher in patients with two or more comorbidities. In our study, increased risk of colonic perforation was observed in patients with ASA scores greater than 3. Handami et al. (21) reported older age, female gender, low BMI, co-existent diseases, and low albumen levels as risk factors of increased perforation rates in hospitalized patients, especially among those admitted to the intensive care unit. In terms of indications, perforation rates have been found to be higher during procedures performed for diagnosing abdominal pain, anemia, Crohn's disease, and bleeding (21).

Perforation rates decrease with the experience of the endoscopist $(3,12)$. However, experience alone is not sufficient to prevent perforations due to the various risk factors discussed previously. Lohsiriwat et al. (26) stated in their study of 10,124 patients that the experience of the endoscopist did not play a significant role in reducing complication rates. In our study, the experience of the endoscopists varied between 2 and 15 years. Of all cases in which perforations were documented, two were by trainees under the control of experienced specialists, three were by endoscopists who had 5 to 10 years of experience, and two were by endoscopists who had 10 to 15 years of experience.

Clinical findings may vary due to several factors. These include time duration from the onset of perforation, degree of abdominal contamination, size and etiology of the perforation, and accompanying diseases of the patient $(7,13,19,26)$. Early surgical intervention is the gold standard approach in the presence of peritoneal irritation findings. Some research- 
ers recommend emergency surgery when sub-diaphragmatic free air is detected, even in the absence of peritoneal irritation. Early and emergent surgical intervention is suggested to be the best treatment strategy to decrease rates of mortality and morbidity (26-30).

Luning et al. (8) reported 35 perforation cases in their study that consisted of 30,366 cases $(0.12 \%)$; surgery was performed on all 35 patients. Seventy-four percent of the perforations occurred in the sigmoid colon, and the mortality rate was found to be $8.6 \%$. Similarly, our mortality rate was $7.6 \%$. In one patient who refused surgical intervention, death occurred due to sepsis. Farley et al. (27) reported their perforation rate as $0.075 \%$ (43 cases) among 57,028 patients; they treated only one patient (2\%) non-surgically. Korman et al. (1) reported $37(0.03 \%)$ perforation cases among their series of 11,6000 patients; they followed up 2 of these patients non-surgically. Factors known to increase morbidity following perforation are time of diagnosis, degree of peritoneal contamination, coexisting diseases, and size of the perforation (31). In our study, the postoperative morbidity rate was found to be $54.4 \%$ (six patients); the most common cause was wound infection.

In recent years, successful results have been reported with new developments in endoscopic techniques.

Multi-canal endoscopic tools, intraluminal or over-the-scope (OTSC) endo-clips, endo-loops, and tissue-sealing materials such as fibrin glue and partially or fullly covered self-expandable metallic stents (SEMS) are some of these new techniques (32). Endo-clip procedures have been reported in the literature since 1997, as well as successful repairs of large intestinal perforations with combinations of endo-clips and endo-loops (33-35). Also, closure of intestinal perforations with injection of fibrin glue has been reported (36). A perforation site of $30 \mathrm{~mm}$ has been reported to be repaired successfully with OTSC (37). Covered SEMS procedures have been used for stricture dilatation in distal colonic anastomosis (38). Aras et al. (39) reported 16 patients with colonoscopic perforation in their series; some cases were treated using minimally invasive techniques. Of 16 patients with colonoscopic perforation, 8 (50\%) were treated by primary repair; 5 (31\%) of these were approached laparoscopically. Bowel resection was performed in three (19\%) patients and diversion in one (6\%) patient. Regarding nonoperative treatment, three (19\%) patients were successfully managed conservatively. Endoscopic closure of the CP was applied using a hemoclip in one (6\%) patient.

In our series, we could not apply endo-clips because they were not available in our clinic at the time of our study. The most important indication for endoscopic repair is the size of the perforation site, which should be less than $10 \mathrm{~mm}$ (12). Although the literature indicates that it is safe, certain conditions must be met for stent placement in colonoscopic perforations. Generally, these conditions are related to the hospital facilities, including the availability of an experienced endoscopist and associated assistant team and the availability of the proper stent and equipment when required (40).

However, we believe that non-surgical follow-up should only be considered for patients who are stable and show no symptoms of peritoneal irritation. The patients should be hospital- ized and followed up without oral intake, intravenous fluid support, and antibiotic prophylaxis. Because of the high risks, non-surgical follow-up should be applied in carefully selected patient groups; the possible risks should be described to patients and their families, and informed consent should be obtained. The current study is limited by its retrospective nature and non-randomized design. Also, we lacked the facilities to perform procedures such as ESD or EMR; as such, we could only assess perforation cases due to endoscopic polypectomy.

\section{CONCLUSION}

The findings from our study showed that patients older than 65 years and those with ASA scores greater than 3 are at higher risk for colonic perforation following therapeutic endoscopy. Colonoscopy is an invasive method associated with an appreciable rate of complications. Early diagnosis and treatment are necessary to reduce mortality and morbidity rates. Unexpected symptoms such as abdominal pain or distention, hypotension, and tachycardia following the procedure should trigger suspicion of colonic perforation, especially in patients identified to carry higher risks.

Ethics Committee Approval: Authors declared that the research was conducted according to the principles of the World Medical Association Declaration of Helsinki "Ethical Principles for Medical Research Involving Human Subjects" (amended in October 2013).

Informed Consent: Written informed consent was obtained from patient who participated in this study.

Peer-review: Externally peer-reviewed.

Author Contributions: Concept - Ş.Ç.; Design - Ş.Ç., B.G.; Supervision - H.B.; Resource - E.Ç., S..B.; Materials - A.G.; Data Collection and/or Processing - Ş.Ç., Ş.B.; Analysis and/or Interpretation - Y.D., B.G.; Literature Search - Y.D., S.Ç.; Writing Manuscript - B.G., Ş.Ç.; Critical Reviews - H.B.

Conflict of Interest: No conflict of interest was declared by the authors.

Financial Disclosure: The authors declared that this study has received no financial support.

\section{REFERENCES}

1. Korman LY, Overholt BF, Box T, Winker CK. Perforation during colonoscopy in endoscopic ambulatory surgical centers. Gastrointest Endosc 2003; 58: 554-557. [CrossRef]

2. Pérez Roldán F, González Carro P, Legaz Huidobro ML, Villafá-ez García MC, Soto Fernández S, de Pedro Esteban A, et al. Endoscopic resection of large colorectal polyps. Rev Esp Enferm Dig 2004; 96: 36-47. [CrossRef]

3. Dafnis G, Ekbom A, Pahlman L, Blomqvist P. Complications of diagnostic and therapeutic colonoscopy within a defined population in Sweden. Gastrointest Endosc 2001; 54: 302-309. [CrossRef]

4. Kavic SM, Basson MD. Complications of endoscopy. Am J Surg 2001; 181: 319-332. [CrossRef]

5. Kang HY, Kang HW, Kim SG, Kim JS, Park KJ, Jung HC, et al. Incidence and management of colonoscopic perfo- rations in Korea. Digestion 2008; 78: 218-223. [CrossRef]

6. Anderson ML, Pasha TM, Leighton JA. Endoscopic perforation of the colon: lessons from a 10-year study. Am J Gastro- enterol 2000; 95: 3418-3422. [CrossRef]

7. Wullstein C, Koppen M, Gross E. Laparoscopic treatment of coIonic perforations related to colonoscopy. Surg Endosc 1999; 13: 484-487. [CrossRef] 
8. Lüning TH, Keemers-Gels ME, Barendregt WB, Tan AC, Rosman C. Colonoscopic perforations: areview of 30.366 patients. Surg Endosc 2007; 21: 994-997. [CrossRef]

9. Rex DK, Lewis BS, Waye JD. Colonoscopy and endoscopic therapy for delayed postpolypectomy hemorrhage. Gastrointest Endosc 1992; 38: 127-129. [CrossRef]

10. Teoh AY, Poon CM, Lee JF, Leong HT, Ng SS, Sung JJ, et al. Outcomes and predictors of mortality and stoma formation in surgical management of colonoscopic perforations: a multicenter review. Arch Surg. 2009; 144: 9-13. [CrossRef]

11. Iqbal CW, Cullinane DC, Schiller HJ, Sawyer MD, Zietlow SP, Farley DR. Surgical management and outcomes of 165 colonoscopic perforations from a single institution. Arch Surg. 2008; 143: 701-706. Discussion 706-707.

12. Rabeneck L, Paszat LF, Hilsden RJ, Saskin R, Leddin D, Grunfeld $E$, et al. Bleeding and perforation after outpatient colonoscopy and their risk factors in usual clinical practice. Gastroenterology. 2008; 135: 1899-1906. [CrossRef]

13. Miranda L, Settembre A, Piccolboni D, Capasso P, Corcione F. latrogenic colonic perforation: repair using laparoscopic technique. Surg Laparosc Endosc Percutan Tech 2011; 21: 170-174. [CrossRef]

14. Lee SH, Choi GS, Lee JH. Laparoscopic treatment of colonic injury caused by colonoscopy. J Korean Soc Coloproctol 2004; 20: 257-262.

15. Rotholtz NA, Laporte M, Lencinas S, Bun M, Canelas A, Mezzadri N. Laparoscopic approach to colonic perforation due to colonoscopy. World J Surg 2010; 34: 1949- 1953. [CrossRef]

16. García Martínez MT, Ruano Poblador A, Galán Raposo L, Gay Fernández AM, Casal Nunez JE. Perforation after colonoscopy: our 16-year experience. Rev Esp Enferm Dig 2007; 99: 588-592.

17. Hall C, Dorricott NJ, Donovan IA, Neoptolemos JP. Colon perforation during colonoscopy: surgical versus conservative management. Br J Surg 1991; 78: 542-544. [CrossRef]

18. Gedebou TM, Wong RA, Rappaport WD, Jaffe $P$, Kahsai D, Hunter GC. Clinical presentation and management of iatro- genic colon perforations. Am J Surg 1996; 172: 454-457. [CrossRef]

19. Araghizadeh FY, Timmcke AE, Opelka FG, Hicks TC, Beck DE. Colonoscopic perforations. Dis Colon Rectum 2001; 44: 713716. [CrossRef]

20. Brayco CM, Kozarek RA, Sanowski RA, Howells T. Diverticular rupture during colonoscopic. Factorfancy Dig Dis Sci 1984; 29: 427-431. [CrossRef]

21. Hamdani U, Naeem R, Haider F, Bansal P, Komar M, Diehl DL, et al. Risk factors for colonoscopic perforation: A populationbased study of 80118 cases. World J Gastroenterol 2013; 19: 3596-3601. [CrossRef]

22. Levin TR, Zhao W, Conell C, Seeff LC, Manninen DL, Shapiro JA, et al. Complications of colonoscopy in an integrated health care delivery system. Ann Intern Med 2006; 145: 880-886. [CrossRef]

23. Arora G, Mannalithara A, Singh G, Gerson LB, Triadafilopoulos G. Risk of perforation from a colonoscopy in adults: a large population-based study. Gastrointest Endosc 2009; 69: 654-664. [CrossRef]

24. Gatto NM, Frucht H, Sundararajan V, Jacobson JS, Grann VR, Neugut Al. Risk of perforation after colonoscopy and sigmoid- oscopy: a population-based study. J Natl Cancer Inst 2003; 95: 230-236. [CrossRef]

25. Nomura E, Takagi S, Kikuchi T, Negoro K, Takahashi S, Kinouchi $Y$, et al. Efficacy and safety of endoscopic balloon dilation for Crohn's strictures. Dis Colon Rectum 2006; 49: 59-67. [CrossRef]

26. Lohsiriwat V. Colonoscopic perforation: incidence, risk factors, management and outcome. World J Gastroenterol. 2010; 16: 425-430. [CrossRef]

27. Farley DR, Bannon MP, Zietlow SP, Pemberton JH, Ilstrup DM, Larson DR. Management of colonoscopic perforations. Mayo Clin Proc. 1997; 72: 729-733. [CrossRef]

28. Matharoo GS, Goldfarb MA. Treatment and outcomes of iatrogenic colon perforations at a community teaching hospital. Am Surg. 2012; 78: 975-978.

29. Hagel AF, Boxberger F, Dauth W, Kessler HP, Neurath MF, Raithel $M$. Colonoscopy associated perforation: a 7-year survey of inhospital frequency, treatment and outcome in a German university hospital. Colorectal Dis 2012; 14: 1121-1125. [CrossRef]

30. Van der Sluis FJ, Loffeld RJ, Engel AF. Outcome of surgery for colonoscopic perforation. Colorectal Dis. 2012; 14: e187-190. [CrossRef]

31. Garbay JR, Suc B, Rotman N, Fourtanier G, Escat J. Multicentre study of surgical complications of colonoscopy. Br J Surg 1996; 83: 42-44. [CrossRef]

32. Barbagallo F, Castello G, Latteri S, Grasso E, Gagliardo S, La Greca $\mathrm{G}$, et al. Succesful endoscopic repair of an unusual colonoic perforation following polypectomy using an endoclip device. World J Gastroenterol 2007; 13: 2889-2891.

33. Yoshikane H, Hidano H, Sakakibara A, Ayakawa T, Mori S, Kawashima $\mathrm{H}$, et al. Endoscopic repair by clipping of iatrogenic colonic perforation. Gastrointest Endosc 1997; 46: 464-466. [CrossRef]

34. Trecca A, Gaj F, Gagliardi G. Our experience with endoscopic repair of large colonoscopic perforations and review of the literature. Tech Coloproctol 2008; 12: 315-321. [CrossRef]

35. Nakagawa $Y$, Nagai T, Soma W, Okawara H, Nakashima $H$, Tasaki T, et al. Endoscopic closure of a large ERCP-related lateral duodenal perforation by using endoloops and endoclips. Gastrointest Endosc 2010; 72: 216-217. [CrossRef]

36. Mocciaro F, Curcio G, Tarantino I, Barresi L, Spada M, Petri SL, et al. Tulip bundle technique and fibrin glue injection: unusual treatment of colonic perforation. World J Gastroenterol 2011; 17: 1088-1090.

37. Gubler C, Bauerfeind P. Endoscopic closure of iatrogenic gastrointestinal tract perforations with the over-the-scope clip. Digestion 2012; 85: 302-307. [CrossRef]

38. Kim SW, Lee WH, Kim JS, Lee HN, Kim SJ, Lee SJ. Successful management of colonic perforation with a covered metal stent. Korean J Intern Med 2013; 28: 715-717. [CrossRef]

39. Aras A, Oran E, Seyit H, Karabulut M, Gök I, Aliş H. Colonoscopic Perforations, What is Our Experience in a Training Hospital? Surg Laparosc Endosc Percutan Tech. 2016; 26: 44-48. [CrossRef]

40. Gürbulak B, Gürbulak EK, Akgün IE, Büyükaşık K, Bektaş H. Endoscopic stent placement in the management of malignant colonic obstruction: Experiences from two centers. Ulus Cerrahi Derg 2015; 31: 132-137. [CrossRef] 